\title{
Ventral Striatal Noradrenergic Mechanisms Contribute to Sensorimotor Gating Deficits Induced by Amphetamine
}

\author{
Karen M Alsene', Katie Fallace' and Vaishali P Bakshi*,' \\ 'Department of Psychiatry and Neuroscience Training Program, University of Wisconsin-Madison, Madison, WI, USA
}

\begin{abstract}
The psychotomimetic drug D-amphetamine (AMPH), disrupts prepulse inhibition (PPI) of the startle response, an operational measure of sensorimotor gating that is deficient in schizophrenia patients. Historically, this effect has been attributed to dopaminergic substrates; however, AMPH also increases norepinephrine (NE) levels, and enhancement of central NE transmission has been shown recently to disrupt PPI. This study examined the extent to which NE might participate in AMPH-induced disruptions of PPI and increases in locomotor activity, another classic behavioral effect of $\mathrm{AMPH}$, by determining whether antagonism of postsynaptic NE receptors blocked these effects. Separate groups of male Sprague-Dawley rats received either the $\alpha$ I receptor antagonist, prazosin $(0,0.3,1 \mathrm{mg} / \mathrm{kg})$, or the $\beta$ receptor antagonist timolol $(0,3,10 \mathrm{mg} / \mathrm{kg}$ ) before administration of $\mathrm{AMPH}(0$ or I mg/ $/ \mathrm{kg}$ ) before testing for PPI or locomotor activity. As an initial exploration of the anatomical substrates underlying possible $\alpha$ I receptor-mediated effects on AMPH-induced PPI deficits, the $\alpha$ I receptor antagonist terazosin $(0$ or $40 \mu \mathrm{g} / 0.5 \mu \mathrm{l})$ was microinfused into the nucleus accumbens shell (NAccSh) in conjunction with systemic AMPH administration before startle testing in a separate experiment. Prazosin, but not timolol, blocked AMPH-induced hyperactivity; both drugs reversed AMPH-induced PPI deficits without altering baseline startle responses. Interestingly, AMPH-induced PPI deficits also were partially blocked by terazosin in NAccSh. Thus, behavioral sequelae of AMPH (PPI disruption and hyperactivity) may be mediated in part by NE receptors, with $\alpha$ I receptors in NAccSh possibly having an important role in the sensorimotor gating deficits induced by this psychotomimetic drug.

Neuropsychopharmacology (2010) 35, 2346-2356; doi:10.1038/npp.2010.106; published online 4 August 2010
\end{abstract}

Keywords: startle; noradrenergic; noradrenaline; schizophrenia; locomotion; psychosis

\section{INTRODUCTION}

Prepulse inhibition (PPI) refers to the reduction in the magnitude of the startle response that normally is observed when a low intensity prestimulus is presented immediately before a startling stimulus (Graham, 1975; Hoffman and Ison, 1980; Ison and Hoffman, 1983), and is used as a measure of sensorimotor gating. Several decades of research have established deficient PPI as an exemplar of the information-processing deficits that are observed in multiple psychiatric illnesses, and PPI disturbances are a well-accepted endophenotype of schizophrenia (Braff et al, 2001b, 2008). To identify the neurochemical modulators and neuroanatomical circuits underlying these clinically observed deficits in sensorimotor gating, the neural substrates of PPI have been analyzed extensively in animal models (Geyer, 2008; Swerdlow et al, 2008).

*Correspondence: Dr VP Bakshi, Department of Psychiatry, UWMadison SMPH, 600I Research Park Boulevard., Madison, WI 537I9, USA, Tel: + (608) 265 6062, Fax: + (608) 2653050 ,

E-mail: vbakshi@wisc.edu

Received 21 February 2010; revised 23 June 2010; accepted 24 June 2010
One method for mimicking clinically manifested PPI deficits in rats is through the administration of psychotomimetic drugs such as amphetamine (AMPH). AMPH has long been known to produce psychotic symptoms in humans that closely resemble the symptoms of schizophrenia (Charalampous and Hug, 1963; Kokkinidis and Anisman, 1981; Snyder, 1973), and also can disrupt PPI in humans (Hutchison and Swift, 1999; Hutchison et al, 1999; Kumari et al, 1998), although see (Swerdlow et al, 2002). In rodents, AMPH disrupts PPI when given systemically (Kinney et al, 1999; Mansbach et al, 1988; Ott and Mandel, 1995; Ralph et al, 1999; Sills, 1999; Swerdlow et al, 2006) or directly into the brain (Wan et al, 1995; Wan and Swerdlow, 1996). To date, these effects have been attributed to the ability of AMPH to release dopamine (DA), because it is well documented that direct DA agonists disrupt PPI and DA receptor antagonists reverse these deficits (Mansbach et al, 1988; Swerdlow et al, 1986, 1994; Wan and Swerdlow, 1993). Clearly, DA receptors have a critical role in the PPI-disruptive effects of AMPH, given that AMPH-induced PPI deficits are reversed by DA receptor antagonists (Swerdlow et al, 2006).

Nevertheless, AMPH also increases extracellular levels of norepinephrine (NE) (Carr and Moore, 1969; Kuczenski and 
Segal, 1992; Robertson et al, 2009) and some of the behavioral effects of AMPH that previously were attributed to its actions on DA systems have since been shown to also require stimulation of NE receptors (Auclair et al, 2004; Drouin et al, 2002a,b). For example, antagonism of $\alpha 1$ noradrenergic receptors blocks AMPH-induced hyperactivity (Blanc et al, 1994; Dickinson et al, 1988), and $\beta \mathrm{NE}$ receptors mediate the effects of AMPH on arousal (Berridge and Morris, 2000). Yet, whether NE receptors mediate AMPH-induced PPI deficits remains to be determined.

Newly emerging evidence supports the regulation of PPI by NE. The NE receptor agonist, cirazoline, disrupts PPI (Carasso et al, 1998; Shilling et al, 2004; Varty et al, 1999) through activation of central $\alpha 1$ receptors (Alsene et al, 2006). Conversely, antagonism of $\alpha 1 \mathrm{NE}$ receptors blunts the PPI-disruptive effects of other psychotomimetic drugs that also indirectly increase NE levels, such as phencyclidine and cocaine (Bakshi and Geyer, 1997; van der Elst et al, 2006). Mice lacking $\alpha 2 \mathrm{~A}$ NE receptors show exaggerated deficits in PPI after administration of AMPH (Lahdesmaki et al, 2004); as $\alpha 2$ receptors function primarily as autoreceptors whose blockade or removal would result in an increase in NE levels (Hein et al, 1999; Starke et al, 1989), this finding is consistent with the notion that increasing central $\mathrm{NE}$ transmission reduces PPI. Thus, it is possible that the well-documented PPI-disrupting effects of AMPH could in part be mediated by indirect stimulation of postsynaptic $\mathrm{NE}$ receptors as a result of the potent NE-releasing properties of AMPH (Robertson et al, 2009).

NE receptors are classified into three main subtypes: $\alpha 1$, $\alpha 2$, and $\beta$, with $\alpha 1$ and $\beta$ receptors as the principal moieties that mediate postsynaptic effects of NE transmission (Pupo and Minneman, 2001). The present experiments tested the hypothesis that AMPH produces its behavioral effects through enhanced NE transmission by determining if blockade of postsynaptic NE receptors with either the $\alpha 1$ antagonist prazosin or the $\beta$ antagonist timolol would prevent AMPH-induced deficits in PPI or AMPH-induced hyperactivity, which is another well-known consequence of AMPH administration in rodents (Berridge, 2006). As an initial exploration of putative neuroanatomical substrates for NE mediation of AMPH effects on PPI, the ability of an $\alpha 1$ receptor antagonist microinfused into the nucleus accumbens shell (NAccSh) to block AMPH-induced PPI deficits was also examined, because NAccSh is known to mediate AMPH-induced PPI deficits and is also heavily innervated by NE-containing terminals (Berridge et al, 1997; Delfs et al, 1998; Wan and Swerdlow, 1996). To the best of our knowledge, these studies are the first to systematically examine if forebrain NE receptors contribute to the sensorimotor gating deficits produced by AMPH.

\section{MATERIALS AND METHODS}

\section{Subjects}

In total, 158 experimentally naïve male Sprague-Dawley rats (Harlan Laboratories, Madison WI, USA) were housed in pairs in clear polycarbonate cages in a light- and temperature-controlled vivarium with lights on at 0700 hours and off at 1900 hours; all testing occurred between 1000 hours and 1600 hours. Food and water were available ad libitum. On arrival, rats were acclimated to the vivarium for 1 week with daily handling; no procedures or tests occurred during that time. Facilities and procedures complied with animal use and care guidelines from the National Institutes of Health of the United States, and were approved by the Institutional Animal Care and Use Committee of the University of Wisconsin.

\section{Startle and PPI Testing}

Startle chambers (San Diego Instruments, San Diego, CA, USA) consisted of nonrestrictive Plexiglas cylinders resting inside a ventilated and illuminated sound-attenuating cabinet. A high-frequency loudspeaker inside the chamber produced both a continuous background noise and the various acoustic stimuli. The whole-body startle response caused vibrations of the Plexiglas cylinder, which were then converted into analog signals by a piezoelectric unit attached to the platform. These signals were digitized and stored by a microcomputer and interface unit. Monthly calibrations were performed on the chambers to ensure accuracy. Sound levels were measured using the $\mathrm{dB}(\mathrm{A})$ scale.

The startle session used a continuous background noise of $65 \mathrm{~dB}$ that was presented alone for $5 \mathrm{~min}$ at the beginning of the session, and remained on throughout the session. The test session consisted of presentation of (in a pseudorandom order) 120-dB Pulse-Alone trials (a 40-ms, 120-dB broadband burst), Prepulse + Pulse trials (20-ms noises that were 3,9 , or $15 \mathrm{~dB}$ above the background noise and were presented $100 \mathrm{~ms}$ before the onset of the 120 -dB pulse), and No Stimulus trials (only the background noise). There were 16 presentations of each of the Prepulse + Pulse trials, 24 Pulse-Alone trials, and 16 No Stimulus trials, with an average of $15 \mathrm{~s}$ between consecutive trials. The first and last four trials of the session were Pulse-Alone presentations that were not included in PPI or startle magnitude calculations, but were used to stabilize average startle responses for the remainder of the session, since the most marked habituation of startle responses occurs with the first several presentations of the startling stimulus (Geyer et al, 1990).

\section{Activity Cages}

Locomotion and rearing were measured using a Photobeam Activity System from San Diego Instruments that consisted of wire-floor clear plastic cages (with no food or water) surrounded by a grid of photobeams. Interruptions in the horizontal beams provided a measure of cage crossings (locomotion) and breaks in the vertical beams measured rearing.

\section{Surgery and Microinfusions}

For experiment 5, rats were anesthetized with a xylazine/ ketamine mixture $(80 \mathrm{mg}$ ketamine and $12 \mathrm{mg}$ xylazine per $\mathrm{ml}$ of the mixture; Phoenix Scientific, St Joseph, MO, USA) and secured in a stereotaxic frame (Kopf Instruments, Tujunga, CA, USA). Stainless steel cannulae (23 gauge, Small Parts, Miami Lakes, FL, USA) were implanted and affixed to the skull with dental cement (Lang Dental Mfg, 
Wheeling, IL, USA) and anchoring screws (Plastics One, Roanoke, VA, USA), and were aimed bilaterally at the NAccSh using the atlas of Pellegrino and Cushman (1967), with nosebar set to $5.0 \mathrm{~mm}$ above interaural zero. Surgical coordinates from bregma were: $+3.2 \mathrm{~mm} \mathrm{AP} ; \pm 1.0 \mathrm{~mm}$ $\mathrm{LM} ;-5.2 \mathrm{~mm} \mathrm{DV}$ (with injectors extending an additional $2.5 \mathrm{~mm}$ beyond cannulae tips for a final DV coordinate of -7.7). Wire stylets were placed in the cannulae to prevent blockage. Rats recovered for a week with daily health checks and handling before any procedures or testing occurred.

For microinfusions, stylets were removed, cannulae were cleaned with a dental broach (Henry Schein, Melville, NY, USA), and stainless steel injectors were inserted (30-gauge, Small Parts). The injectors were attached with polyethylene tubing (PE-10, Becton Dickinson, Sparks, MD, USA) to 10- $\mu$ glass Hamilton syringes (Hamilton, Reno, NV, USA) mounted on a microdrive pump (Harvard Apparatus, Holliston, MA, USA). Microinfusions were administered at a rate of $0.32 \mu \mathrm{l} / \mathrm{min}$ with a final volume of $0.5 \mu \mathrm{l}$ per side. Injectors were left in place for one additional minute before stylets were replaced to allow for absorption of the infusate into the tissue. Several days before the experiment, rats received a mock infusion in which injectors were lowered but no infusate was delivered to acclimate them to the infusion procedure.

\section{Drugs}

D-AMPH sulfate, prazosin hydrochloride, timolol maleate, and terazosin hydrochloride were obtained from Sigma (St Louis, MO, USA); all drugs except for prasozin were dissolved in sterile isotonic saline. Prazosin was dissolved with sonication in a vehicle solution comprised of $95 \%$ distilled water plus 5\% DMSO (Sigma). This solution was used as the vehicle injection for all prazosin experiments.

\section{Experimental Design}

Five experiments were conducted using separate groups of experimentally naïve rats for each experiment. For all PPI studies, rats underwent three baseline startle/PPI tests, with the final baseline occurring 2-3 days before the experiment to create equally matched treatment groups (on the basis of PPI and startle magnitude) for subsequent drug testing; for experiment 5 (NAccSh), the mock infusion was conducted immediately before this final baseline startle/ PPI test. Similarly, for all locomotor activity studies, rats were habituated for $2 \mathrm{~h}$ to the photocell cages 2-3 days before the experiment, and equally matched treatment groups were designated for the subsequent drug testing on the basis of total activity levels from the habituation day. Doses and injection parameters for prazosin, AMPH, timolol, and terazosin were based on previous experiments in which these drugs were found to affect PPI or antagonize behavioral effects induced by agonists for their respective receptors (Bakshi and Geyer, 1997; Colussi-Mas et al, 2005).

Experiment 1: Prazosin/AMPH/PPI. Rats $(N=7-11$ per dose) received intraperitoneal (IP) injection of the $\alpha 1$ receptor antagonist prazosin (vehicle, 0.3 , or $1 \mathrm{mg} / \mathrm{kg}$ ) $25 \mathrm{~min}$ before a subcutaneous (SC) injection of saline or AMPH $(1 \mathrm{mg} / \mathrm{kg})$ and were tested in startle chambers $5 \mathrm{~min}$ later. After 1 week, the protocol was repeated, but within each prazosin dose group, rats that had previously received saline received AMPH and vice versa. Thus, prazosin dose was a between-subjects factor, and AMPH treatment was within-subjects.

Experiment 2: Timolol/AMPH/PPI. Using the same crossover design as experiment 1 , rats $(N=12-15$ per dose $)$ received IP injection of the $\beta$ NE receptor antagonist, timolol $(0,3$, or $10 \mathrm{mg} / \mathrm{kg}) 5 \mathrm{~min}$ before SC AMPH injection $(0,1 \mathrm{mg} / \mathrm{kg})$, and were tested in startle chambers $5 \mathrm{~min}$ later.

Experiment 3: Prazosin/AMPH/activity. Rats $(N=6-7$ per group, with pretreatment and treatment as between-subjects factors) were placed in activity cages for $30 \mathrm{~min}$, then given IP injection of prazosin $(0,0.3$, or $1 \mathrm{mg} / \mathrm{kg})$, placed back in the activity cages, and 25 min later given SC injection of AMPH (0 or $1 \mathrm{mg} / \mathrm{kg})$. Motor activity was then measured for $60 \mathrm{~min}$.

Experiment 4: Timolol/AMPH/activity. Using the same design as experiment 3 , rats $(N=7-9$ per group) were placed in activity cages for $50 \mathrm{~min}$, given IP injections of timolol $(0,3$, or $10 \mathrm{mg} / \mathrm{kg})$, placed back in activity cages, and $5 \mathrm{~min}$ later given SC injection of AMPH $(0$ or $1 \mathrm{mg} / \mathrm{kg})$ before measurement of motor activity for 60 more minutes.

Experiment 5: Terazosin in NAccSh/AMPH/PPI. Rats $(N=12)$ received SC injections of AMPH $(0$ or $1 \mathrm{mg} / \mathrm{kg})$ followed by intra-NAccSh infusion of terazosin (0 or $40 \mu \mathrm{g} /$ $0.5 \mu \mathrm{l}$; used because of its solubility in isotonic saline) and then immediately were tested in startle chambers. In a counterbalanced order over four test days, all rats received all four pretreatment/treatment combinations, with at least $96 \mathrm{~h}$ separating consecutive tests.

\section{Data Analysis}

For PPI analysis, the startle response to the onset of the 120$\mathrm{dB}$ burst was recorded for $100 \mathrm{~ms}$ for each Pulse-Alone and Prepulse + Pulse trial. Two measurements (startle magnitude and PPI) were calculated from these values for each rat for each of the different treatment conditions. Startle magnitude was calculated by taking the average of the startle responses to the Pulse-Alone trials. PPI was calculated as a percent score for each Prepulse + Pulse trial type: $\%$ PPI $=100-\{[($ startle response for Prepulse + Pulse trial)/(startle response for Pulse-Alone trial) $] \times 100\}$. For experiments 1-2, startle data were calculated with twoway analysis of variance (ANOVA) using pretreatment (prazosin or timolol) as a between-subjects factor and treatment (AMPH) as a within-subjects factor. PPI data were analyzed using these same factors in a three-way ANOVA with prepulse as an additional (within-subjects) factor. For experiment 5, all factors (pretreatment, treatment, prepulse intensity) were within-subjects.

Total cage crossings (locomotion) and rears were calculated in 15-min intervals over the 2-h test session. The data from the last four intervals (last $60 \mathrm{~min}$ of the session) corresponded to post-AMPH injection time-points, and were analyzed with separate three-factor ANOVAs with 
time (intervals) as the repeated measure and pretreatment and treatment as between-subjects variables. For all experiments, post hoc analyses were conducted using Newman-Keuls tests, with $\alpha$ level set at 0.05 .

Histological verification of injector placements was carried out by an experimenter that was blind to the behavioral data to confirm localization of microinfusions in experiment 5 to the NAccSh. Rats were perfused transcardially with $0.9 \%$ saline followed by $10 \%$ formalin; brains were removed, sliced $(60 \mu \mathrm{m})$, and stained with Cresyl violet; and sections were examined under a light microscope. Final sample size for the behavioral data reflects the omission of one rat whose placements were found to fall outside of the shell of the accumbens.

\section{RESULTS}

\section{Experiment 1: The $\alpha 1$ NE Receptor Antagonist Prazosin} Reverses AMPH-Induced PPI Deficits

As expected, there was a main effect of prepulse intensity $(\mathrm{F}(2,22)=110, P<0.001)$, which is a well-known parametric feature of PPI whereby increasing prepulse intensities elicit higher levels of PPI (Braff et al, 2001a). For the sake of brevity, reporting of this main effect, which was observed in all of the PPI experiments, is not repeated throughout the results section. Figure 1 illustrates the effects of prazosin and AMPH on PPI. There was a main effect of AMPH treatment $(\mathrm{F}(1,22)=11.40, P<0.003)$, with AMPH producing a robust decrease in PPI at all three prepulse intensities $(P<0.01-P<0.001)$ (Figure 1a). There was no main effect of prazosin pretreatment $(\mathrm{F}(2,22)=1.4$, NS),

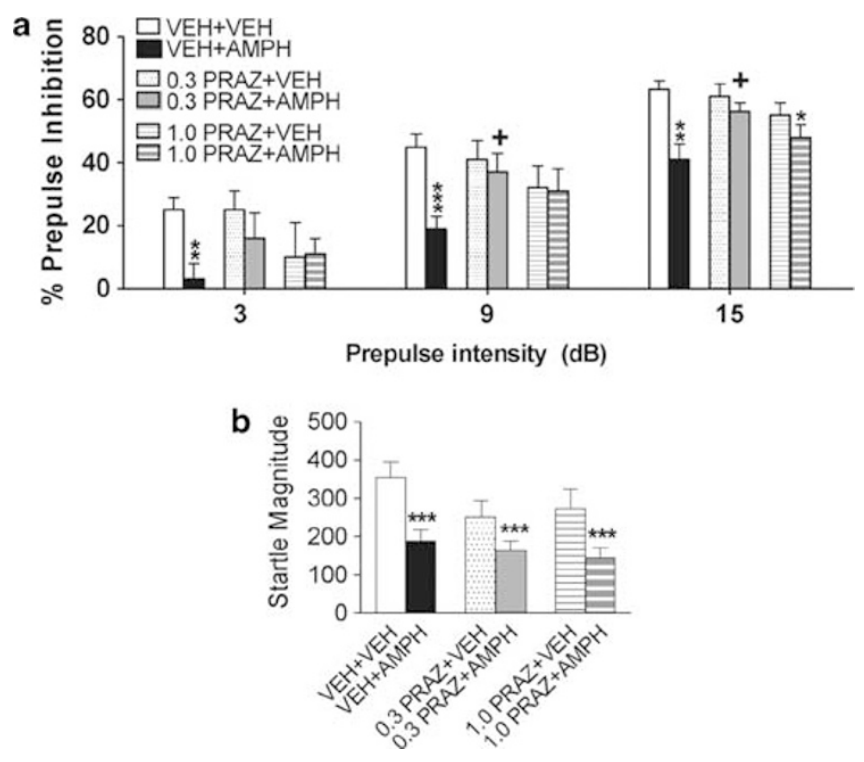

Figure I Effects of pretreatment with the $\alpha$ | receptor antagonist, prazosin (PRAZ), on (a) prepulse inhibition and (b) startle magnitude after amphetamine (AMPH) administration. Values represent means \pm SEM for each drug condition. Doses are in $\mathrm{mg} / \mathrm{kg}$. Prepulse intensity indicates decibels above the background noise level. $* P<0.05$, $* * P<0.01$, **** $P<0.00$ I relative to $\mathrm{VEH}+\mathrm{VEH}$ condition; ${ }^{+} P<0.05$ relative to $\mathrm{VEH}$ $+\mathrm{AMPH}$ condition. but there was a significant interaction between prazosin pretreatment and AMPH treatment on PPI $(F(2,22)=6.2$, $P<0.008)$. Subsequent post hoc tests showed that the low dose of prazosin $(0.3 \mathrm{mg} / \mathrm{kg})$ reversed AMPH-induced deficits in PPI at the 9- and 15-dB prepulse intensities $(P<0.05)$, with PRAZ + AMPH PPI levels not differing significantly from those of the $\mathrm{VEH}+\mathrm{VEH}$ condition.

The effects of prazosin and AMPH on baseline startle responses are shown in Figure $1 \mathrm{~b}$. There was a main effect of AMPH treatment $(\mathrm{F}(1,22)=62.5, P<0.001)$ with $\mathrm{AMPH}$ producing a decrease in startle magnitude $(P<0.001)$, which has been reported previously (Swerdlow et al, 2001). Significant pretreatment or pretreatment $\times$ treatment effects were not observed. Thus, prazosin did not alter the AMPH-induced reduction in startle magnitude, which taken together with the PPI data indicate that the reversal of AMPH-induced PPI deficits by prazosin is dissociable from effects on baseline startle magnitude.

\section{Experiment 2: The $\beta$ NE Receptor Antagonist Timolol Reverses AMPH-Induced Deficits in PPI}

The results from the timolol/AMPH experiment are shown for PPI in Figure 2a and for startle responses in Figure $2 b$. There was a main effect of AMPH treatment $(\mathrm{F}(1,39)=9.1$, $P<0.005)$ with AMPH significantly reducing PPI at multiple prepulse intensities $(P<0.05-P<0.001)$. There was no main effect of timolol pretreatment $(\mathrm{F}(2,39)=1.3$, NS), but there was a significant interaction between timolol pretreatment $\times$ AMPH treatment $(\mathrm{F}(2,39)=3.3, \quad P<0.046)$. Post hoc analyses indicated that like prazosin, the lower dose of timolol $(3 \mathrm{mg} / \mathrm{kg})$ also reduced $\mathrm{AMPH}$-induced PPI deficits at multiple prepulse intensities $(P<0.05)$.
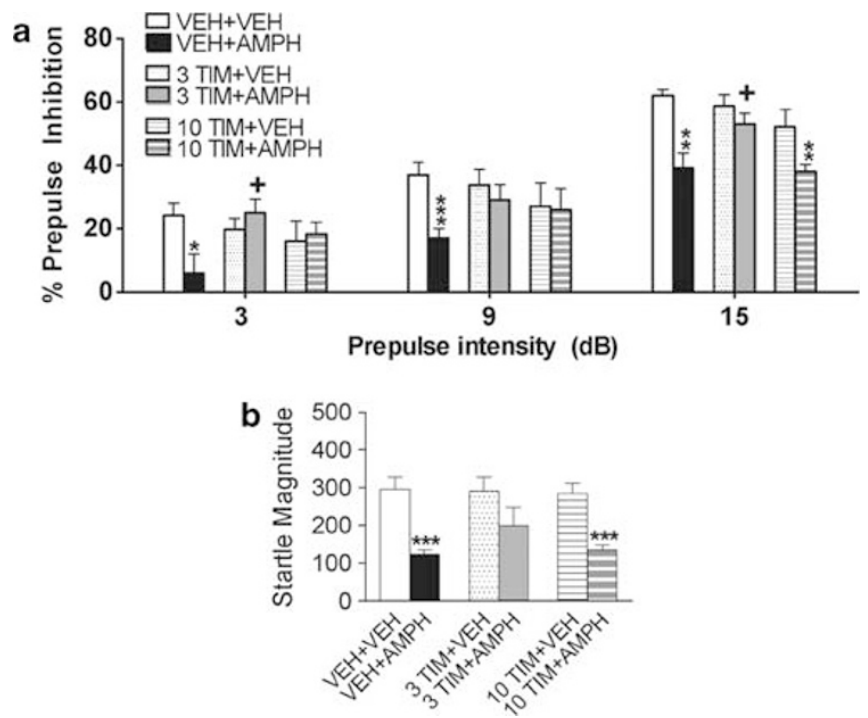

Figure 2 Effects of pretreatment with the $\beta$ receptor antagonist, timolol (TIM), on (a) prepulse inhibition and (b) startle magnitude after amphetamine (AMPH) administration. Values represent means \pm SEM for each drug condition. Doses are in $\mathrm{mg} / \mathrm{kg}$. Prepulse intensity indicates decibels above the background noise level. $* P<0.05$, $* * P<0.01$, **** $P<0.00$ I relative to $\mathrm{VEH}+\mathrm{VEH}$ condition; ${ }^{+} P<0.05$ relative to $\mathrm{VEH}$ $+\mathrm{AMPH}$ condition. 
There was a significant main effect of AMPH on baseline startle $(\mathrm{F}(1,39)=76.3, P<0.001)$, with AMPH producing a decrease in baseline startle magnitude compared with the vehicle + vehicle condition $(P<0.001)$. There was no main effect of timolol pretreatment on baseline startle $(\mathrm{F}(2,39)=0.5, \mathrm{NS})$ nor a significant timolol pretreatment $\times \mathrm{AMPH}$ treatment interaction $(\mathrm{F}(2,39)=2.3$, NS). Thus, timolol did not block the decrease in baseline startle magnitude caused by AMPH, but like prazosin, did reverse AMPH-induced PPI deficits.

\section{Experiment 3: Prazosin Reduces AMPH-Induced Hyperactivity}

The effects of prazosin and AMPH on locomotion (horizontal beam breaks that provide a measure of cage crossings) and rearing (vertical beam breaks) are shown in Figures $3 \mathrm{a}$ and $\mathrm{b}$, respectively. There was a main effect of AMPH treatment on locomotion $(\mathrm{F}(1,35)=87.8, P<0.001)$, with AMPH increasing cage crossings (VEH + AMPH group $v s \mathrm{VEH}+\mathrm{VEH}$ group) at all timepoints after its administration $(P<0.001)$. There was also a main effect of prazosin pretreatment $(\mathrm{F}(2,35)=3.8, P<0.032)$. Importantly, there was a significant interaction between prazosin pretreatment and AMPH treatment $(\mathrm{F}(2,35)=4.1, P<0.026)$. There was a main effect of time $(F(3,105)=3.9, P<0.01)$ that likely arose from the significant interaction between time and AMPH treatment $(\mathrm{F}(3,105)=5.4, P<0.002)$. There was no significant interaction between time and prazosin pretreatment $(F(6,105)=0.3$, NS) and no three-way interaction between time, prazosin pretreatment, and AMPH treatment $(\mathrm{F}(6,105)=0.8, \mathrm{NS})$. Subsequent post hoc tests revealed that the high dose of prazosin $(1.0 \mathrm{mg} / \mathrm{kg})$ partially reversed AMPH-induced increases in locomotion at all timepoints after AMPH administration such that the 1.0 PRAZ + AMPH group had significantly lower values than the VEH + AMPH group $(P<0.05$ at all timepoints), but still had significantly higher values than the VEH + VEH group $(P<0.05)$. The lower dose of prazosin had no effect.

Similar to the profile observed with locomotion, there was a main effect of AMPH treatment on rearing $(\mathrm{F}(1,35)=58.6, \quad P<0.001)$, with $\mathrm{AMPH}$ increasing the number of rears at all four post-injection timepoints
$(P<0.001)$. There was also a main effect of prazosin pretreatment $(\mathrm{F}(2,35)=13.0, P<0.001)$, and a significant interaction between prazosin pretreatment and AMPH treatment $(\mathrm{F}(2,35)=12.1, P<0.001)$, indicating that prazosin also reversed AMPH-induced increases in rearing. There was no significant main effect of time $(F(3,105)=0.4$, NS), nor significant interactions between time and prazosin pretreatment $(F(6,105)=0.6$, NS) nor a three-way time $\times$ prazosin pretreatment $\times$ AMPH treatment interaction $(\mathrm{F}(6,105)=1.1, \mathrm{NS})$; there was a significant interaction between time and AMPH treatment $(\mathrm{F}(3,105)=5.7$, $P<0.005)$. Subsequent post hoc tests showed that there was a partial reversal of AMPH-induced increases in rearing by the low dose of prazosin $(0.3 \mathrm{mg} / \mathrm{kg})(P<0.05)$ and a full reversal by the high dose $(1.0 \mathrm{mg} / \mathrm{kg})$ at all four timepoints $(P<0.01)$.

\section{Experiment 4: Timolol Does not Reduce AMPH-Induced Hyperactivity}

The results from experiment 4 are shown in Figure 4 and divided into locomotion (Figure 4a) and rearing (Figure $4 \mathrm{~b}$ ). In the case of locomotion, there was a significant main effect of AMPH treatment $(F(1,42)=381$, $P<0.001$ ). Timolol pretreatment, however, had no effect on locomotion as there was no significant main effect of pretreatment $(F(2,42)=1.7, \mathrm{NS})$, nor an interaction between timolol pretreatment and AMPH treatment $(\mathrm{F}(2,42)=1.8, \mathrm{NS})$. There was a main effect of time $(\mathrm{F}(3,126)=5.9, \quad P<0.001)$ and significant interactions between time and timolol pretreatment $(\mathrm{F}(6,126)=2.2$, $P<0.044)$ and time and AMPH treatment $(\mathrm{F}(3,126)=3.7$, $P<0.014)$, but there was no significant time $\times$ pretreatment $\times$ treatment interaction $(\mathrm{F}(6,126)=1.2$, NS). Post hoc analyses showed that all groups receiving AMPH had higher levels of locomotion than the VEH + VEH group $(P<0.001)$, and that there were no differences between timolol $+\mathrm{AMPH}$ groups and the VEH + AMPH group.

The profile for rearing was similar, with AMPH-induced hyperactivity reflected in the significant main effect of AMPH treatment $(\mathrm{F}(1,42)=129.4, P<0.001)$. There were no effects of timolol pretreatment on rearing $(\mathrm{F}(2,42)=1.7$, NS) nor were there significant interactions between timolol
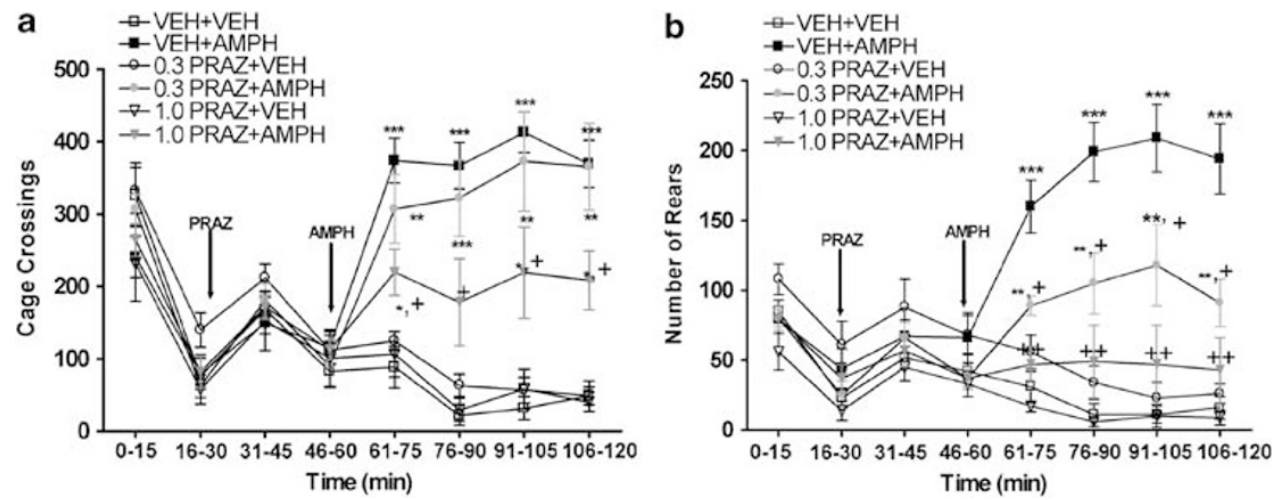

Figure 3 Effects of pretreatment with the $\alpha$ l receptor antagonist, prazosin (PRAZ), on amphetamine (AMPH)-induced locomotion (a) and rearing (b) Values represent means \pm SEM for each drug condition. Doses are in $\mathrm{mg} / \mathrm{kg}$. Arrows indicate the timepoint in the test session at which drugs were administered. ${ }^{*} P<0.05$, ${ }^{*} * P<0.01$, ${ }^{*} * * P<0.00$ I relative to $\mathrm{VEH}+\mathrm{VEH}$ condition; ${ }^{+} P<0.05,{ }^{++} P<0.01$, relative to $\mathrm{VEH}+\mathrm{AMPH}$ condition. 

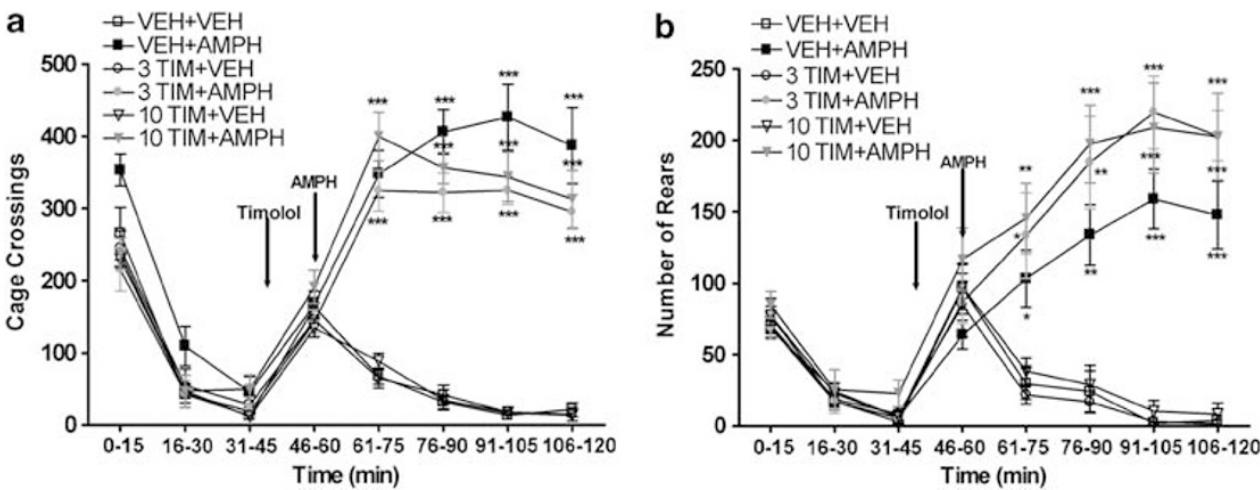

Figure 4 Effects of pretreatment with the $\beta$ receptor antagonist, timolol (TIM), on amphetamine (AMPH)-induced locomotion (a) and rearing (b). Values represent means \pm SEM for each drug condition. Doses are in $\mathrm{mg} / \mathrm{kg}$. Arrows indicate the timepoint in the test session at which drugs were administered. $* P<0.05$, $* * P<0.01$, **** $P<0.00$ I relative to $\mathrm{VEH}+\mathrm{VEH}$ condition.

pretreatment and $\mathrm{AMPH}$ treatment $(\mathrm{F}(2,42)=1.5$, NS). There was a main effect of time $(\mathrm{F}(3,126)=4.6, P<0.005)$ and a significant interaction between time and $\mathrm{AMPH}$ treatment $(\mathrm{F}(3,126)=21.1, P<0.001)$. There was no significant interaction between time and timolol pretreatment $(F(6,126)=0.4, N S)$ and no significant three-way interaction between time, pretreatment, and treatment $(\mathrm{F}(6,126)=0.2$, NS). Post hoc tests showed that all AMPHtreated groups had significantly higher rearing values than the VEH + VEH group, at every post-AMPH timepoint $(P<0.05-\mathrm{P}<0.001)$. Thus, timolol did not reduce AMPHinduced increases in rearing.

\section{Experiment 5: Intra-Accumbens Terazosin Reverses AMPH-Induced PPI Deficits}

As in previous experiments, there was a main effect of AMPH treatment on PPI $(F(1,11)=7.82, P<0.017)$, with AMPH treatment producing a robust decrease in PPI at all three prepulse intensities $(P<0.01) \quad$ (Figure 5a). There was no main effect of terazosin pretreatment on PPI $(\mathrm{F}(1,11)=0.9$, NS), however, there was a significant interaction between terazosin pretreatment and AMPH treatment $(\mathrm{F}(1,22)=9.2, P<0.012)$. Subsequent post hoc tests showed that PPI levels at the $3-\mathrm{dB}$ and $9-\mathrm{dB}$ prepulse intensities were significantly higher $(P<0.05)$ for the terazosin + AMPH condition, compared with PPI levels for the vehicle + AMPH condition; terazosin + AMPH values did not differ significantly from vehicle + vehicle values (Figure 5). Injector placements for this experiment are shown in Figure 6. These results indicate that antagonism of $\alpha 1 \mathrm{NE}$ receptors in NAccSh significantly reduced the deficit in PPI caused by systemic AMPH. As with the previous experiments, this normalization of PPI deficits was independent of alterations in startle magnitude, because the reduction in startle magnitude that was caused by AMPH (main effect of treatment $(\mathrm{F}(1,11)=43.3, P<0.001)$ ) was not changed by intra-NAccSh terazosin (no significant main effect of terazosin $(F(1,11)=0.5, N S)$ nor a terazosin $\mathrm{X}$ AMPH interaction $(F(1,11)=0.1, N S))$. Thus, regardless of drug infusion into NAccSh, AMPH-induced startle values were significantly lower than those for the vehicle + vehicle condition $(P<0.01)$.
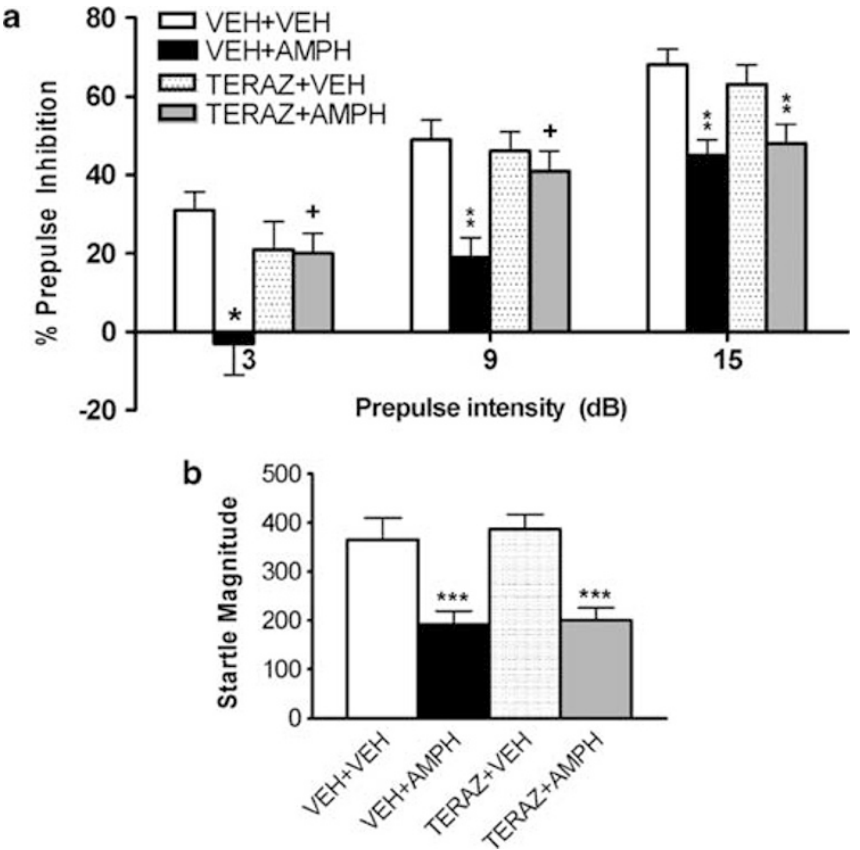

Figure 5 Effects of intra-nucleus accumbens shell (NAccSh) infusion of the $\alpha \mid$ receptor antagonist, terazosin (TERAZ), on (a) prepulse inhibition and (b) startle magnitude after systemic amphetamine (AMPH) administration. Values represent means \pm SEM for each drug condition. Prepulse intensity indicates decibels above the background noise level. $* P<0.05$, ${ }^{*} * P<0.01$, $* * * P<0.001$, relative to $\mathrm{VEH}+\mathrm{VEH}$ condition; ${ }^{+} P<0.05$ relative to $\mathrm{VEH}+\mathrm{AMPH}$ condition.

\section{DISCUSSION}

This study tested the hypothesis that indirect stimulation of postsynaptic NE receptors contributes to AMPH-induced deficits in PPI. Consistent with many previous reports, AMPH disrupted PPI and increased exploratory behaviors (locomotion and rearing) (Blanc et al, 1994; Dickinson et al, 1988; Mansbach et al, 1988; Ott and Mandel, 1995; Swerdlow et al, 1990, 2003). Both the $\alpha 1$ receptor antagonist, prazosin, and the $\beta$ receptor antagonist, timolol, blocked deficits in PPI induced by AMPH, indicating that $\alpha 1$ and $\beta \mathrm{NE}$ receptors are necessary for AMPH-induced deficits in PPI. 


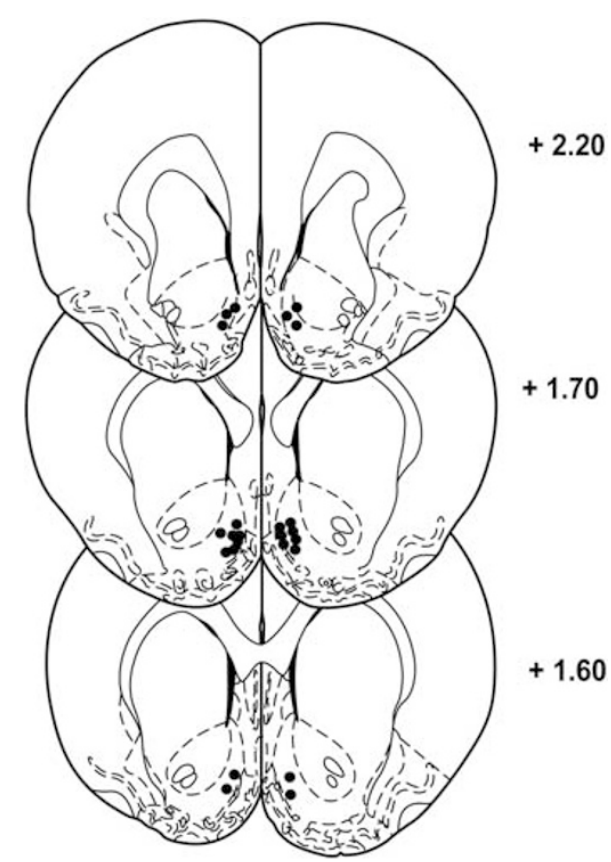

Figure 6 Injector tip locations within the nucleus accumbens shell for rats in experiment 5. Numbers are $\mathrm{mm}$ from bregma.

Prazosin also attenuated AMPH-induced increases in locomotion and rearing. Taken together, these data indicate that postsynaptic NE receptor activation, particularly at $\alpha 1$ receptors, underlies two classic behavioral features of AMPH administration: disruption of sensorimotor gating and hyperactivity. The present findings also for the first time indicate that the NAccSh may be an anatomical substrate through which increased NE transmission might mediate AMPH-induced PPI deficits, as intra-shell infusion of the $\alpha 1$ receptor antagonist terazosin also prevented PPI deficits arising from systemic AMPH administration. Thus, indirect stimulation of $\alpha 1$ and $\beta$ NE receptors by AMPH because of its enhancement of NE transmission (Florin et al, 1994; Kuczenski and Segal, 1992; Robertson et al, 2009) leads to a reduction in sensorimotor gating. Interestingly, the failure of the high doses of prazosin and timolol to reverse AMPH-induced PPI deficits could be due to the tendency of these doses to reduce PPI on their own, and may reflect the existence of an optimal range of postsynaptic NE transmission that supports PPI, with either reductions or elevations from this equilibrium resulting in decreased PPI levels.

AMPH-induced decreases in startle magnitude were not affected by either prazosin or timolol in spite of the potent reversal of $A M P H$-induced PPI deficits by these drugs, suggesting that these NE receptor-mediated effects of AMPH on PPI cannot be accounted for by simple nonspecific changes in startle magnitude. Direct stimulation of postsynaptic NE receptors also disrupts PPI in a manner that is dissociable from changes in startle reactivity (Alsene et al, 2006). There similarly was a dissociation between the effects of NE receptor antagonists on AMPH-induced deficits in PPI and hyperactivity, suggesting that the mechanisms subserving these two well-documented behavioral sequelae of AMPH may differ. Prazosin, but not timolol, blocked AMPH-induced increases in locomotion and rearing, suggesting that indirect stimulation of $\alpha 1$, but not $\beta$ receptors, contributes to AMPH-induced hyperactivity under the current experimental conditions. These findings agree with earlier studies (Blanc et al, 1994; Colussi-Mas et al, 2005; Dickinson et al, 1988; Drouin et al, $2002 \mathrm{a}, \mathrm{b})$. The same doses of timolol that were ineffective in blocking AMPH-induced hyperactivity did potently reverse AMPH-induced PPI deficits in these studies, which is consistent with previous indications that these doses of timolol are behaviorally active (Colussi-Mas et al, 2005). Thus, both $\alpha 1$ and $\beta$ receptors contribute to the PPIdisruptive effects of AMPH, but the locomotor activityenhancing effects of AMPH appear to be more reliant on $\alpha 1$ receptors. This dissociation could result from the differing anatomical distributions of $\alpha 1$ and $\beta$ receptors (Nicholas et al, 1996; Pupo and Minneman, 2001); for example, it is possible that there may be a set of distinct sites that support $\beta$ receptor-mediated disruptions of PPI but not hyperactivity.

The present finding that antagonism of $\alpha 1$ receptors within the NAccSh markedly reduced PPI deficits after systemic AMPH administration suggests that indirect stimulation of accumbens-localized $\alpha 1$ receptors is one central anatomical substrate through which AMPH decreases sensorimotor gating. This site is innervated heavily by NE-synthesizing neuron terminals, and nucleus accumbens NE efflux increases five- to sevenfold after systemic AMPH administration (Berridge et al, 1997; Delfs et al, 1998; McKittrick and Abercrombie, 2007). Furthermore, AMPH-induced hyperactivity is reduced by antagonism of $\alpha 1$ NE receptors in prefrontal cortex (PFC) (Darracq et al, 1998). Given that PFC is known to modulate PPI (Lacroix et al, 2000; Shoemaker et al, 2005), it would be of interest in future studies to determine if, similar to the present finding with the NAccSh, blockade of $\alpha 1$ receptors in PFC would also reduce AMPH-induced PPI deficits. In addition, immunohistochemical and autoradiographic studies indicate the presence of $\alpha 2$ and $\beta$ NE receptors within the nucleus accumbens (Carvalho et al, 2010; Ma et al, 2006; Palacios and Kuhar, 1982). Given that the present AMPHinduced PPI deficits were also blocked by systemic timolol (a $\beta$ receptor antagonist), it also would be of interest to determine if antagonism of these other receptors in accumbens similarly blocks these PPI deficits.

Although it has been known for many years that NE regulates attention, arousal, memory, and cognition, its role in sensorimotor gating has not been well studied (AstonJones and Cohen, 2005; Berridge, 2008; Robbins and Arnsten, 2009). Given the presence of PPI deficits in several psychiatric illnesses in which putative NE system dysfunction is hypothesized (Braff et al, 2001b), it is reasonable to predict that alterations in NE transmission could underlie PPI deficits in these illnesses. Genetically altered mice lacking $\alpha 2 \mathrm{~A}$ or $\alpha 2 \mathrm{C}$ receptors show a disruption of basal PPI and an enhancement of AMPH-induced PPI deficits because of increased NE transmission centrally (resulting from removal of autoreceptor-mediated inhibition over NE synthesis and release) (Lahdesmaki et al, 2002, 2004; Sallinen et al, 1998). Thus, it is somewhat surprising that systemic clonidine, an agonist for $\alpha 2$ receptors, failed to reverse $A M P H$-induced $P P I$ deficits in a recent study (Swerdlow et al, 2006). Yet, the dose of AMPH that was 
used in that study $(4.5 \mathrm{mg} / \mathrm{kg})$ was much higher than that of this study; when lower doses of AMPH are given, clonidine does antagonize AMPH-induced behavioral effects (Vanderschuren et al, 2003). It would be interesting to determine whether PPI deficits produced by low doses of AMPH can be blocked by clonidine. Regardless, the present findings clearly indicate that blockade of postsynaptic $\alpha 1$ and $\beta \mathrm{NE}$ receptors prevents PPI deficits induced by AMPH, which is in agreement with previous reports that stimulation of postsynaptic NE receptors disrupts PPI (Alsene et al, 2006; Carasso et al, 1998). Importantly, for the first time a specific neuroanatomical substrate, the NAccSh, has been implicated in this effect.

There is reason to believe that NE regulation of PPI may vary across anatomical subregions of the nucleus accumbens, as has been observed with other systems (Caine et al, 2001; Hara and Pickel, 2008; Kodsi and Swerdlow, 1997; Pothuizen et al, 2005; Swerdlow et al, 2001; Wan et al, 1994). After systemic AMPH administration, NE release is greater in accumbens shell vs core (McKittrick and Abercrombie, 2007). Coupled with the finding that accumbens lacks $\alpha 2$ autoreceptor-mediated inhibition of NE (Schoffelmeer $e t a l$, 1998), one might expect that AMPH-induced NE release within shell would not be mitigated by the normal opposing influence on NE transmission of autoregulatory shut-off mechanisms, resulting in markedly elevated levels of NE in this site available to stimulate postsynaptic NE receptors. Our lab has found that direct stimulation of $\alpha 1$ and $\beta$ adrenoceptors in accumbens shell, but not core, disrupts PPI (Alsene et al, 2007), thus the present finding that blocking $\alpha 1$ receptors within accumbens shell reverses AMPH-induced PPI deficits is consistent with this mechanism.

The present findings add to the growing consensus that certain behavioral effects of AMPH that previously were attributed primarily to increases in DA transmission in fact are mediated also in part by NE (Berridge and Morris, 2000; Blanc et al, 1994; Dickinson et al, 1988; Drouin et al, 2002a). A complex set of site- and receptor-dependent interactions between DA and NE systems contribute to other behavioral effects of AMPH (Darracq et al, 1998; Drouin et al, 2002a, b; Espejo and Minano, 2001; Pascucci et al, 2007; Tassin, 1998; Vanderschuren et al, 1999, 2003; Villegier et al, 2003). Whether or not similar dynamics regulate PPI remains to be determined, as there also is evidence for independent actions of each system on PPI (Bakshi and Geyer, 1997; Carasso et al, 1998; Swerdlow et al, 2006). Thus, the nature of potential DA-NE interactions in PPI remains to be defined further; nevertheless, the present results indicate a prominent role for $\alpha 1 \mathrm{NE}$ receptors in accumbens shell in the PPI-disruptive effects of AMPH.

It has been argued that actions at NE receptors may contribute to the unique effects of second-generation antipsychotics (Bakshi and Geyer, 1997; Baldessarini et al, 1992; Breier, 1994; Svensson, 2003), but clinically, the question of whether NE receptor-based medications are effective antipsychotics has not been well examined. There is some evidence for enhancement of antipsychotic function by compounds that reduce central NE transmission or block postsynaptic NE receptors, suggesting the possibility of NEbased therapeutics as adjunct treatments for schizophrenia, but there are also examples of no clinical improvement with these compounds in schizophrenia (Berlant, 1987; Freedman et al, 1982, 2001; Maas et al, 1995; Wahlbeck et al, 2000).

Perhaps less controversial is the notion that drugs that modify central NE transmission have clinical utility in the treatment of several other psychiatric illnesses in which cognitive NE-based dysfunction is hypothesized (Arnsten et al, 2007; Bhidayasiri, 2005; Boehnlein and Kinzie, 2007). Among these conditions are attention deficit disorder, Tourette's syndrome, and post-traumatic stress disorder, all of which have been associated with deficient PPI (Braff $e t a l$, 2001b). Thus, NE-based PPI deficits may provide a good model for a separate subset of affected individuals (Alsene et al, 2006; Swerdlow et al, 2006). The present results provide an important new insight into the pathways that may be involved in these deficits by showing that within the NAccSh, enhanced NE transmission may underlie the PPI-disruptive effects of AMPH. Indeed, as subsequent studies systematically will delineate the specific circuits mediating NE-based PPI deficits, novel DA-independent substrates of sensorimotor gating abnormalities may emerge and shed further insight into the deficits that are manifest clinically. As these studies underscore, postsynaptic NE receptors do have a significant role in the PPIdisruptive effects of AMPH, which is one of the most widely used pharmacological models of deficient sensorimotor gating, thus these findings provide a solid foundation for future investigation into novel systems that regulate this important form of information processing.

\section{ACKNOWLEDGEMENTS}

This work was funded by RO1 MH075980 (VPB) and F31 MH077465 (KMA).

\section{DISCLOSURE}

Dr Bakshi has no conflicts to report. Dr Alsene was a graduate student in Dr Bakshi's laboratory during the time when the studies in this paper were completed, and while the paper was written, thus has no conflicts to report. At the present time, Dr Alsene is a full-time employee (Medical Writer) with Covance, which has no relationship to the present work. At no time during the course of the studies described in this paper was any author receiving any materials or compensation from any outside company.

\section{REFERENCES}

Alsene KM, Carasso BS, Connors EE, Bakshi VP (2006). Disruption of prepulse inhibition after stimulation of central but not peripheral alpha-1 adrenergic receptors. Neuropsychopharmacology 31: 2150-2161.

Alsene KM, Ramaker MJ, Bakshi VP (2007). Effects of noradrenergic receptor stimulation in the nucleus accumbens and anterior medial prefrontal cortex on prepulse inhibition. Soc Neurosci Abstr 33: 499-527.

Arnsten AF, Scahill L, Findling RL (2007). Alpha2-adrenergic receptor agonists for the treatment of attention-deficit/ hyperactivity disorder: emerging concepts from new data. J Child Adolesc Psychopharmacol 17: 393-406. 
Aston-Jones G, Cohen JD (2005). Adaptive gain and the role of the locus coeruleus-norepinephrine system in optimal performance. J Comp Neurol 493: 99-110.

Auclair A, Drouin C, Cotecchia S, Glowinski J, Tassin JP (2004). 5-HT2A and alpha1b-adrenergic receptors entirely mediate dopamine release, locomotor response and behavioural sensitization to opiates and psychostimulants. Eur J Neurosci 20: 3073-3084.

Bakshi VP, Geyer MA (1997). Phencyclidine-induced deficits in prepulse inhibition of startle are blocked by prazosin, an alpha-1 noradrenergic antagonist. J Pharmacol Exp Ther 283: 666-674.

Baldessarini RJ, Huston-Lyons D, Campbell A, Marsh E, Cohen BM (1992). Do central antiadrenergic actions contribute to the atypical properties of clozapine? Br J Psychiatry Suppl 17: 12-16.

Berlant JL (1987). One more look at propranolol for the treatment of refractory schizophrenia. Schizophr Bull 13: 705-714.

Berridge CW (2006). Neural substrates of psychostimulantinduced arousal. Neuropsychopharmacology 31: 2332-2340.

Berridge CW (2008). Noradrenergic modulation of arousal. Brain Res Rev 58: 1-17.

Berridge CW, Morris MF (2000). Amphetamine-induced activation of forebrain EEG is prevented by noradrenergic beta-receptor blockade in the halothane-anesthetized rat. Psychopharmacology (Berl) 148: 307-313.

Berridge CW, Stratford TL, Foote SL, Kelley AE (1997). Distribution of dopamine beta-hydroxylase-like immunoreactive fibers within the shell subregion of the nucleus accumbens. Synapse 27: 230-241.

Bhidayasiri R (2005). Tourette's syndrome: old syndrome, new insights and new treatment. J Med Assoc Thai 88(Suppl 4): S339-S347.

Blanc G, Trovero F, Vezina P, Herve D, Godeheu AM, Glowinski J et al (1994). Blockade of prefronto-cortical alpha 1-adrenergic receptors prevents locomotor hyperactivity induced by subcortical D-amphetamine injection. Eur J Neurosci 6: 293-298.

Boehnlein JK, Kinzie JD (2007). Pharmacologic reduction of CNS noradrenergic activity in PTSD: the case for clonidine and prazosin. J Psychiatr Pract 13: 72-78.

Braff DL, Geyer MA, Light GA, Sprock J, Perry W, Cadenhead KS et al (2001a). Impact of prepulse characteristics on the detection of sensorimotor gating deficits in schizophrenia. Schizophr Res 49: 171-178.

Braff DL, Geyer MA, Swerdlow NR (2001b). Human studies of prepulse inhibition of startle: normal subjects, patient groups, and pharmacological studies. Psychopharmacology (Berl) 156: 234-258.

Braff DL, Greenwood TA, Swerdlow NR, Light GA, Schork NJ (2008). Advances in endophenotyping schizophrenia. World Psychiatry 7: 11-18.

Breier A (1994). Clozapine and noradrenergic function: support for a novel hypothesis for superior efficacy. J Clin Psychiatry 55(Suppl B): 122-125.

Caine SB, Humby T, Robbins TW, Everitt BJ (2001). Behavioral effects of psychomotor stimulants in rats with dorsal or ventral subiculum lesions: locomotion, cocaine self-administration, and prepulse inhibition of startle. Behav Neurosci 115: 880-894.

Carasso BS, Bakshi VP, Geyer MA (1998). Disruption in prepulse inhibition after alpha-1 adrenoceptor stimulation in rats. Neuropharmacology 37: 401-404.

Carr LA, Moore KE (1969). Norepinephrine: release from brain by d-amphetamine in vivo. Science 164: 322-323.

Carvalho AF, Mackie K, Van Bockstaele EJ (2010). Cannabinoid modulation of limbic forebrain noradrenergic circuitry. Eur $J$ Neurosci 31: 286-301.

Charalampous KD, Hug A (1963). Psychosis following the use of amphetamines. Med Rec Ann 56: 31-32.

Colussi-Mas J, Panayi F, Scarna H, Renaud B, Berod A, Lambas-Senas L (2005). Blockade of beta-adrenergic receptors prevents amphetamine-induced behavioural sensitization in rats: a putative role of the bed nucleus of the stria terminalis. Int J Neuropsychopharmacol 8: 569-581.

Darracq L, Blanc G, Glowinski J, Tassin JP (1998). Importance of the noradrenaline-dopamine coupling in the locomotor activating effects of D-amphetamine. J Neurosci 18: 2729-2739.

Delfs JM, Zhu Y, Druhan JP, Aston-Jones GS (1998). Origin of noradrenergic afferents to the shell subregion of the nucleus accumbens: anterograde and retrograde tract-tracing studies in the rat. Brain Res 806: 127-140.

Dickinson SL, Gadie B, Tulloch IF (1988). Alpha 1- and alpha 2-adrenoreceptor antagonists differentially influence locomotor and stereotyped behaviour induced by d-amphetamine and apomorphine in the rat. Psychopharmacology (Berl) 96: 521-527.

Drouin C, Blanc G, Villegier AS, Glowinski J, Tassin JP (2002a). Critical role of alphal-adrenergic receptors in acute and sensitized locomotor effects of D-amphetamine, cocaine, and GBR 12783: influence of preexposure conditions and pharmacological characteristics. Synapse 43: 51-61.

Drouin C, Darracq L, Trovero F, Blanc G, Glowinski J, Cotecchia S et al (2002b). Alpha1b-adrenergic receptors control locomotor and rewarding effects of psychostimulants and opiates. J Neurosci 22: 2873-2884.

Espejo EF, Minano J (2001). Adrenergic hyperactivity and metanephrine excess in the nucleus accumbens after prefrontocortical dopamine depletion. J Neurophysiol 85: 1270-1274.

Florin SM, Kuczenski R, Segal DS (1994). Regional extracellular norepinephrine responses to amphetamine and cocaine and effects of clonidine pretreatment. Brain Res 654: 53-62.

Freedman R, Kirch D, Bell J, Adler LE, Pecevich M, Pachtman E et al (1982). Clonidine treatment of schizophrenia. Double-blind comparison to placebo and neuroleptic drugs. Acta Psychiatr Scand 65: 35-45.

Friedman JI, Adler DN, Temporini HD, Kemether E, Harvey PD, White L et al (2001). Guanfacine treatment of cognitive impairment in schizophrenia. Neuropsychopharmacology 25: 402-409.

Geyer MA (2008). Developing translational animal models for symptoms of schizophrenia or bipolar mania. Neurotox Res 14: 71-78.

Geyer MA, Swerdlow NR, Mansbach RS, Braff DL (1990). Startle response models of sensorimotor gating and habituation deficits in schizophrenia. Brain Res Bull 25: 485-498.

Graham FK (1975). Presidential Address, 1974. The more or less startling effects of weak prestimulation. Psychophysiology 12: 238-248.

Hara Y, Pickel VM (2008). Preferential relocation of the $\mathrm{N}$-methyl-D-aspartate receptor NR1 subunit in nucleus accumbens neurons that contain dopamine D1 receptors in rats showing an apomorphine-induced sensorimotor gating deficit. Neuroscience 154: 965-977.

Hein L, Altman JD, Kobilka BK (1999). Two functionally distinct alpha2-adrenergic receptors regulate sympathetic neurotransmission. Nature 402: 181-184.

Hoffman HS, Ison JR (1980). Reflex modification in the domain of startle: I. Some empirical findings and their implications for how the nervous system processes sensory input. Psychol Rev 87: 175-189.

Hutchison KE, Swift R (1999). Effect of d-amphetamine on prepulse inhibition of the startle reflex in humans. Psychopharmacology (Berl) 143: 394-400.

Hutchison KE, Wood MD, Swift R (1999). Personality factors moderate subjective and psychophysiological responses to d-amphetamine in humans. Exp Clin Psychopharmacol 7: 493-501.

Ison JR, Hoffman HS (1983). Reflex modification in the domain of startle: II. The anomalous history of a robust and ubiquitous phenomenon. Psychol Bull 94: 3-17. 
Kinney GG, Wilkinson LO, Saywell KL, Tricklebank MD (1999). Rat strain differences in the ability to disrupt sensorimotor gating are limited to the dopaminergic system, specific to prepulse inhibition, and unrelated to changes in startle amplitude or nucleus accumbens dopamine receptor sensitivity. J Neurosci 19: 5644-5653.

Kodsi MH, Swerdlow NR (1997). Reduced prepulse inhibition after electrolytic lesions of nucleus accumbens subregions in the rat. Brain Res 773: 45-52.

Kokkinidis L, Anisman H (1981). Amphetamine psychosis and schizophrenia: a dual model. Neurosci Biobehav Rev 5: 449-461.

Kuczenski R, Segal DS (1992). Regional norepinephrine response to amphetamine using dialysis: comparison with caudate dopamine. Synapse 11: 164-169.

Kumari V, Mulligan OF, Cotter PA, Poon L, Toone BK, Checkley SA et al (1998). Effects of single oral administrations of haloperidol and d-amphetamine on prepulse inhibition of the acoustic startle reflex in healthy male volunteers. Behav Pharmacol 9: 567-576.

Lacroix L, Broersen LM, Feldon J, Weiner I (2000). Effects of local infusions of dopaminergic drugs into the medial prefrontal cortex of rats on latent inhibition, prepulse inhibition and amphetamine induced activity. Behav Brain Res 107: 111-121.

Lahdesmaki J, Sallinen J, MacDonald E, Kobilka BK, Fagerholm V, Scheinin M (2002). Behavioral and neurochemical characterization of alpha(2A)-adrenergic receptor knockout mice. Neuroscience 113: 289-299.

Lahdesmaki J, Sallinen J, MacDonald E, Scheinin M (2004). Alpha2A-adrenoceptors are important modulators of the effects of D-amphetamine on startle reactivity and brain monoamines. Neuropsychopharmacology 29: 1282-1293.

Ma J, Ye N, Cohen BM (2006). Expression of noradrenergic alpha1, serotoninergic 5HT2a and dopaminergic D2 receptors on neurons activated by typical and atypical antipsychotic drugs. Prog Neuropsychopharmacol Biol Psychiatry 30: 647-657.

Maas JW, Miller AL, Tekell JL, Funderburg L, Silva JA, True J et al (1995). Clonidine plus haloperidol in the treatment of schizophrenia/psychosis. J Clin Psychopharmacol 15: 361-364.

Mansbach RS, Geyer MA, Braff DL (1988). Dopaminergic stimulation disrupts sensorimotor gating in the rat. Psychopharmacology (Berl) 94: 507-514.

McKittrick CR, Abercrombie ED (2007). Catecholamine mapping within nucleus accumbens: differences in basal and amphetamine-stimulated efflux of norepinephrine and dopamine in shell and core. J Neurochem 100: 1247-1256.

Nicholas AP, Hokfelt T, Pieribone VA (1996). The distribution and significance of CNS adrenoceptors examined with in situ hybridization. Trends Pharmacol Sci 17: 245-255.

Ott DA, Mandel RJ (1995). Amphetamine sensitivity in open-field activity $v s$ the prepulse inhibition paradigm. Brain Res Bull 37: 219-222.

Palacios J, Kuhar MJ (1982). Beta adrenergic receptor localization in rat brain by light microscopic autoradiography. Neurochem Int 4: 473-490.

Pascucci T, Ventura R, Latagliata EC, Cabib S, Puglisi-Allegra S (2007). The medial prefrontal cortex determines the accumbens dopamine response to stress through the opposing influences of norepinephrine and dopamine. Cereb Cortex 17: 2796-2804.

Pellegrino LJ, Cushman AJ (1967). A stereotaxic atlas of the rat brain. Appleton Century Crofts: New York, pp 22.

Pothuizen HH, Jongen-Relo AL, Feldon J (2005). The effects of temporary inactivation of the core and the shell subregions of the nucleus accumbens on prepulse inhibition of the acoustic startle reflex and activity in rats. Neuropsychopharmacology 30: 683-696.

Pupo AS, Minneman KP (2001). Adrenergic pharmacology: focus on the central nervous system. CNS Spectr 6: 656-662.
Ralph RJ, Varty GB, Kelly MA, Wang YM, Caron MG, Rubinstein $M$ et al (1999). The dopamine D2, but not D3 or D4, receptor subtype is essential for the disruption of prepulse inhibition produced by amphetamine in mice. J Neurosci 19: 4627-4633.

Robbins TW, Arnsten AF (2009). The neuropsychopharmacology of fronto-executive function: monoaminergic modulation. Annu Rev Neurosci 32: 267-287.

Robertson SD, Matthies HJ, Galli A (2009). A closer look at amphetamine-induced reverse transport and trafficking of the dopamine and norepinephrine transporters. Mol Neurobiol 39: 73-80.

Sallinen J, Haapalinna A, Viitamaa T, Kobilka BK, Scheinin M (1998). Adrenergic alpha2C-receptors modulate the acoustic startle reflex, prepulse inhibition, and aggression in mice. J Neurosci 18: 3035-3042.

Schoffelmeer AN, Vanderschuren LJ, van Royen DE, Wardeh G, Hogenboom F, Mulder AH (1998). Lack of alpha2-adrenoceptor autoregulation of noradrenaline release in rat nucleus accumbens slices. Naunyn Schmiedebergs Arch Pharmacol 357: 87-90.

Shilling PD, Melendez G, Priebe K, Richelson E, Feifel D (2004). Neurotensin agonists block the prepulse inhibition deficits produced by a 5-HT(2A) and an alpha(1) agonist. Psychopharmacology (Berl) 175: 353-359.

Shoemaker JM, Saint Marie RL, Bongiovanni MJ, Neary AC, Tochen LS, Swerdlow NR (2005). Prefrontal D1 and ventral hippocampal N-methyl-D-aspartate regulation of startle gating in rats. Neuroscience 135: 385-394.

Sills TL (1999). Amphetamine dose dependently disrupts prepulse inhibition of the acoustic startle response in rats within a narrow time window. Brain Res Bull 48: 445-448.

Snyder SH (1973). Amphetamine psychosis: a 'model' schizophrenia mediated by catecholamines. Am J Psychiatry 130: 61-67.

Starke K, Gothert M, Kilbinger H (1989). Modulation of neurotransmitter release by presynaptic autoreceptors. Physiol Rev 69: 864-989.

Svensson TH (2003). Alpha-adrenoceptor modulation hypothesis of antipsychotic atypicality. Prog Neuropsychopharmacol Biol Psychiatry 27: 1145-1158.

Swerdlow NR, Bongiovanni MJ, Tochen L, Shoemaker JM (2006). Separable noradrenergic and dopaminergic regulation of prepulse inhibition in rats: implications for predictive validity and Tourette syndrome. Psychopharmacology (Berl) 186: 246-254.

Swerdlow NR, Braff DL, Geyer MA, Koob GF (1986). Central dopamine hyperactivity in rats mimics abnormal acoustic startle response in schizophrenics. Biol Psychiatry 21: 23-33.

Swerdlow NR, Braff DL, Taaid N, Geyer MA (1994). Assessing the validity of an animal model of deficient sensorimotor gating in schizophrenic patients. Arch Gen Psychiatry 51: 139-154.

Swerdlow NR, Eastvold A, Karban B, Ploum Y, Stephany N, Geyer MA et al (2002). Dopamine agonist effects on startle and sensorimotor gating in normal male subjects: time course studies. Psychopharmacology (Berl) 161: 189-201.

Swerdlow NR, Geyer MA, Braff DL (2001). Neural circuit regulation of prepulse inhibition of startle in the rat: current knowledge and future challenges. Psychopharmacology (Berl) 156: $194-215$

Swerdlow NR, Mansbach RS, Geyer MA, Pulvirenti L, Koob GF, Braff DL (1990). Amphetamine disruption of prepulse inhibition of acoustic startle is reversed by depletion of mesolimbic dopamine. Psychopharmacology (Berl) 100: 413-416.

Swerdlow NR, Stephany N, Wasserman LC, Talledo J, Shoemaker J, Auerbach PP (2003). Amphetamine effects on prepulse inhibition across-species: replication and parametric extension. Neuropsychopharmacology 28: 640-650.

Swerdlow NR, Weber M, Qu Y, Light GA, Braff DL (2008). Realistic expectations of prepulse inhibition in translational models 
for schizophrenia research. Psychopharmacology (Berl) 199: 331-388.

Tassin JP (1998). Norepinephrine-dopamine interactions in the prefrontal cortex and the ventral tegmental area: relevance to mental diseases. Adv Pharmacol 42: 712-716.

van der Elst MC, Ellenbroek BA, Cools AR (2006). Cocaine strongly reduces prepulse inhibition in apomorphinesusceptible rats, but not in apomorphine-unsusceptible rats: regulation by dopamine D2 receptors. Behav Brain Res 175: 392-398.

Vanderschuren LJ, Beemster P, Schoffelmeer AN (2003). On the role of noradrenaline in psychostimulant-induced psychomotor activity and sensitization. Psychopharmacology (Berl) 169: 176-185.

Vanderschuren LJ, Wardeh G, De Vries TJ, Mulder AH, Schoffelmeer AN (1999). Opposing role of dopamine D1 and D2 receptors in modulation of rat nucleus accumbens noradrenaline release. J Neurosci 19: 4123-4131.

Varty GB, Bakshi VP, Geyer MA (1999). M100907, a serotonin 5-HT2A receptor antagonist and putative antipsychotic, blocks dizocilpine-induced prepulse inhibition deficits in
Sprague-Dawley and Wistar rats. Neuropsychopharmacology 20: 311-321.

Villegier AS, Drouin C, Bizot JC, Marien M, Glowinski J, Colpaert F et al (2003). Stimulation of postsynaptic alpha1b- and alpha2adrenergic receptors amplifies dopamine-mediated locomotor activity in both rats and mice. Synapse 50: 277-284.

Wahlbeck K, Cheine MV, Gilbody S, Ahonen J (2000). Efficacy of beta-blocker supplementation for schizophrenia: a systematic review of randomized trials. Schizophr Res 41: 341-347.

Wan FJ, Geyer MA, Swerdlow NR (1994). Accumbens D2 modulation of sensorimotor gating in rats: assessing anatomical localization. Pharmacol Biochem Behav 49: 155-163.

Wan FJ, Geyer MA, Swerdlow NR (1995). Presynaptic dopamineglutamate interactions in the nucleus accumbens regulate sensorimotor gating. Psychopharmacology (Berl) 120: 433-441.

Wan FJ, Swerdlow NR (1993). Intra-accumbens infusion of quinpirole impairs sensorimotor gating of acoustic startle in rats. Psychopharmacology (Berl) 113: 103-109.

Wan FJ, Swerdlow NR (1996). Sensorimotor gating in rats is regulated by different dopamine-glutamate interactions in the nucleus accumbens core and shell subregions. Brain Res 722: 168-176. 